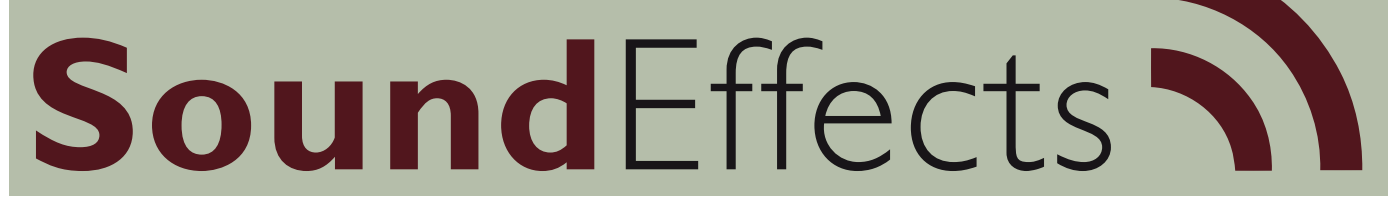

An Interdisciplinary Journal of Sound and Sound Experience

\title{
Rune Søchting
}

\section{Something that speaks}




\section{Abstract}

Taking as its starting point the notion of schizophonia, this paper considers the effects of mediation of the voice. Schizophonia was intended to denote a state of experienced confusion that followed from a distortion of the spatiotemporal conditions of experience caused by media technology. The article asks how these effects are to be considered in a situation characterised by a ubiquitous presence of mediation. Based on these considerations the paper presents an analysis of the work Blanche-Neige Lucie by the French artist Pierre Huyghe. Huyghe's work has explored the often blurred line between fiction and reality and how different accounts of reality intertwine in our experience and memory. In Blanche-Neige Lucie Huyghe explores the voice in relation to the format of film, particularly the figure of dubbing, and how the medial conditions allow for a certain confusion with regard to the questions of identity and memory.

\section{Introduction}

The effects of the ubiquitous modern technology of communication with its ability to technically record, transmit and represent the vocal are a recurring object of investigation. One issue that pertains to the process of technically mediated vocal communication is the question: What exactly is being recorded, transmitted or represented, and what is lost? Another issue concerns the ubiquitous nature of audio technology in the $20^{\text {th }}$ and $21^{\text {st }}$ centuries: What are the consequences of the presence of the technology in itself? Does the fact that the technology of communication is part of everyday situations alter the horizon against which something is perceived, potentially changing its significance?

These concerns have been articulated against the background of dramatic cultural changes significant for the modern era with the introduction and commercial distribution of technologies such as the telephone, the radio and the phonograph. Arguably the bleakest view on the consequences of ubiquitous audio technology is found in the Canadian composer and soundscape theorist R. Murray Schafer's diagnosis of a modern urban environment. His identification of sounds that are transmitted and experienced over a loudspeaker as schizophonic intentionally evokes an image of a technology that surgically and violently separates sounds from their natural origin (Schafer, 1977, p. 90). More generally the modern state of schizophonia is characterised by a confusion where sounds appear spatiotemporally dislocated from their origin and where the technology of transmission makes it possible for a voice to be amplified and multiplied across countless loudspeakers, far beyond the normal reach of a voice emitted from a single body. ${ }^{1}$

There are good reasons to question the somewhat simplistic dichotomy between the pre-modern and modern underlying Schafer's bombastic critique of the modern 
auditory environment. Further, one can argue that the cultural changes his theory is designed to capture inevitably tie his analysis to a particular historical frame.

Nonetheless, even read today Schafer's emphasis on the impact of particular circumstances on the mode of listening provides a valuable perspective for an analysis of mediated sonic phenomena. One could even follow Steven Connor when he suggests that Schafer does not go far enough in his description of the 'detached' sounds: The presence of ubiquitous technology is not a distortion or disruption of an 'original' or normal relationship between sounds and their cause. Rather, perception must be understood against ubiquitous technological mediation as a backdrop and a condition for experience (Connor, 2012). However, this shift in context leaves the question: what is the current significance of a mediated voice?

Obviously the range of this question is beyond the scope of this article. I wish to pursue this question with particular regard to aesthetic phenomena where mediated voice is a recurrent theme. More specifically the focus of the article is the work of the French artist Pierre Huyghe who, in a number of works, has explored the figure of the mediated voice. Following an initial account of themes associated with the schizophonic voice, the latter part of the article is devoted to an analysis of his works.

\section{Voices of the non-present}

While the notion of schizophonic applies to the experience of mediated audio phenomena in a broad sense, the effect of mediation seems to find its critical apotheosis when it comes to the phenomenon of the human voice.

The particular quality of a schizophonic voice is often associated with the experience of a de-centred subject and evokes connotations of a disturbed, if not pathological state where voices are heard as coming from nowhere. Even if the phenomenon is a product of advanced technology, its experiential qualities link it to much more primitive tricks of the senses, most significantly to ventriloquism, as Connor's elaborate analysis suggests (Connor, 2001).

At the same time the schizophonic voice involves a certain ambiguity in the immediate presence of an audible voice and the spatiotemporal distance to its origin that is the result of the mediation. This experienced ambiguity can serve as a catalyst for existentialist questions. A striking literary example is found in the first chapter of 'The Guermantes Way' in Marcel Proust's In search of lost time, where the protagonist, during a holiday, has a conversation with his grandmother on the telephone. The conversation affects the protagonist deeply. With only the presence of her voice over the telephone the protagonist senses an immediate intimacy that he has never experienced before. He feels an urge to be with her, and following the conversation he travels to Paris to see her only to find that the closeness he experienced over the phone is now lost and the woman he encounters is a stranger. 
The passage has been given a tandem-like reading by the Slovenian philosophers Mladen Dolar (2006) and Slavoj Žižek (2012). Their Lacanian readings identify the voice as an objet petit $a$, an object of lack that serves as a constitutive element in the ongoing dynamic of the production of order in the experience of reality. To them, the telephone-transmitted voice, as described in Proust's text, suggests an apparent jump in causality that makes this dynamic apparent.

This seemingly paradoxical experience is not unique for technically mediated audio phenomena. For example, there is clear resonance between the experience described by Proust and Roland Barthes' famous account of the photographic image in Camera Lucida (Barthes, 2010).

For Barthes, the nature of the photographic image (particularly the portrait image) is found in a temporal paradox. The image subject presented in the photograph has an immediacy to it which appears at odds with the viewer's knowledge that the depicted moment is past. In the image there is a sense of something real that is simultaneously something inevitably lost. For this reason, the photographic image is associated with death as a kind of memento mori.

In a similar fashion death is present in Marcel Proust's protagonist's experience. The telephone is a medium that enables the immediate presence of a voice while simultaneously bringing the premonition of the absence of the one speaking.

It is hardly necessary to adopt the Lacanian framework of Žižek and Dolar to account for the experienced paradoxes that accompany the schizophonic technology and the connotations of death triggered by technology's ability to evoke the presence of someone absent. ${ }^{2}$ A number of artists have explored this theme, for example the Swedish artist Erik Bünger. In the first of a trilogy of video essays titled A Lecture on Schizophonia (2007-2011) Bünger muses over a number of schizophonic situations, among them the popular phenomenon of a musical performer singing duets with a recording of a deceased performer, such as Nathalie Cole singing a duet with her father Nat King Cole. ${ }^{3}$

In this way, the phonograph and the telephone find their place next to other devices in the $20^{\text {th }}$ century, allowing for a technically mediated experience, which also establishes a tension with regard to what is sensorially perceived.

\section{From anxiety of 'where' and 'when' to 'who'}

In general, the schizophonic experience is characterised by the tension between a naïve sense of causality and a spatiotemporal fluidity introduced by way of a technology of mediation. The schizophonic technology enables a particular mode of recalling and memorising events and traces of individuals, yet it also introduces a certain lack of clarity regarding the 'when' and 'where' of what is experienced which sets the frame for an imaginary virtual presence. 
The schizophonic voice phenomenon finds its resonance within a modern sensibility related to 'new' technologies such as the telephone and the phonograph. However, given that a naturalisation of the presence of technology has taken place, one can question to what extent the schizophonic effect and its underlying rational are transferrable to a current context, or whether the analysed effect should be considered within the historical context it was proposed.

As Jonathan Sterne, among others, has proposed, this aspect must be taken into account (Sterne, 2003). ${ }^{4}$ An interesting point raised by Steven Connor is that the modern anxiety articulated by Schafer regarding the schizophonic experience conceived today involves an element of nostalgia. It involves a longing for a time when a confused modern world could be juxtaposed against a pre-modern, naïvely perceived order. In order to take this into account Connor suggests replacing the term schizophonia with 'panophonia' (Connor, 2012). This suggestion would imply a shift in focus away from the spatiotemporal distortion of the schizophonic experience and instead consider the mediated voices against the horizon of the ubiquity of mediation. The focus here would be on the affects that define and govern a relational network and the formats that help shape this network.

This will be the focus of the remaining part of this article. Its point of departure is the work of the French artist Pierre Huyghe. In a number of remarkable works Huyghe has explored how identity is produced through medial circumstances. Here the question pertaining to the schizophonic experience is less about a loss of clarity regarding the spatiotemporal context and more about how identity and knowledge are produced by the particular features of mediation. As such, what is at stake could be phrased as a shift from a tension regarding the experienced 'when' and 'where' to a tension regarding a 'who'.

I will try to make this tension apparent through a reading of the video work Blanche-Neige Lucie, which takes the mediated voice as its central motif. This work explores both an experiential dynamic specific to the medial conventions of film as a format and a relational dynamic related to how identity is a product of circumstances. I will elucidate this through Michel Chion's theory of the voice in cinema and further relate the reading of this work to other works by Huyghe.

\section{The voice of Snow White}

The light is turned on and a film studio is revealed. In the centre of the image is a woman in her 60 s facing the camera. She sits silently in front of the empty studio that is filmed in one continuous shot lasting the full four minutes of the work. In the bottom of the screen are subtitles where the woman, Lucie Dolène, tells the story of how she got to be the voice of Snow White for the French distribution of Walt Disney's film, and how she 'gave her voice' to the animated girl figure. She explains 
how, for the first time, she sang Snow White's song at a school party, how she later met Walt Disney, and she recounts her experience of listening over headphones in the dubbing studio and how she felt that she was becoming one with the character. She explains how she later had the feeling of having somehow lost her voice to the character, and how she had to go through a legal battle to regain the right to her voice.

During the video, while the subtitles appear on the screen, Dolène starts humming, first quietly, then louder and then she opens her mouth and sings 'Un jour mon prince viendra'. After the song she falls quiet and remains silent until the video ends.

Pierre Huyghe's documentary video Blanche-Neige Lucie from 1997 is shot on 16-mm film. It is one of several works, including the titles Dubbing (1996), The Third Memory (2000) and One Million Kingdoms (2001), which explore how questions of identity and memory are negotiated within the film format. ${ }^{5}$ The matter at stake in these works is not just how identity is represented in a film. Rather, the works thematically explore how identity is produced by way of the film format. A recurrent element is how the voice serves as a mark for identity.

Blanche-Neige Lucie explores the object voice on two levels:

1. On one level the work investigates how the voice as an object is represented within the film format and how various modes of representation carry a certain aesthetic potential.

2. On another level the mediation of the voice in the film format is explored as a process in which identity and memory are produced. Here the motif of dubbing is crucial.

In the following I will account for both levels.

\section{The voice in cinema - a multiplicity of voices}

In his work Huyghe explores how the voice as an object is presented in the format of a film. Historically the voice as a phenomenon has been integrated in film in a number of different ways.

The Jazz Singer by Alan Crosland from 1927 is considered the historical mark, where the audible voice was introduced to the commercially distributed film. However, if one follows the French composer and theoretician Michel Chion in The Voice in Cinema, the audience of films produced prior to this one did not experience a lack of sound. To the audience of silent films, it was as if the action took place behind soundproof glass. The voice was made present through the visible movements of the actors, and text slides provided the literal content of the vocal expression. Rather, as Chion notes with reference to Marguerite Duras, what differentiated the silent film from the 'talking' film was the nature of the voices that were present. The early 
films entailed an experienced richness, in that the silence opened a space for an imaginary vocal phenomenon (Chion, 1999, p. 9). Following this, the introduction of sound did not mean the addition of what had been missing, but rather the elimination of the presence of the possible imagined voice. Similar observations are made by Pierre Huyghe regarding the modes of presence of a voice:

I have noticed that the timbre of my interior, silent voice is the same as my physical voice, but without its coarseness; the same voice as that with which I speak, but without its hesitations, because it shuns all experience. It is not a material, physical sound, but the psychic imprint of a sound. Also, when I see a subtitled film, there is a clash between my silent voice that is reading and the strange voice that I hear. The text projects an acoustic image that becomes a unique mental image, vague but still shared. Silent movies allow a multitude of possible mental voices that the spectator imagines, or more exactly that are in harmony with the spectator's silent voice, whereas in talkies only one single voice is possible. (Huyghe, 1997, p. 45)

\section{The acousmêtre}

According to Chion, the introduction of the audible voice in film was motivated by an ambition to increase the level of experienced realism. This realist ambition was achieved by synchronising separately recorded audio and video material in postproduction.

Chion notes that the addition of an audible voice synchronised to the image of an actor speaking did not add any substantial new aspect to the film. However, the mode of production did allow for an alternative presence of voice. It allowed for the occurrence of a voice that is out of synch with what is immediately visible in the film image. Chion terms the phenomenon of an audible voice that cannot immediately be associated with a visible speaker the 'acousmêtre', with reference to Pierre Schaeffer's term the 'acousmatic' (Chion, 1999, p. 9). The acousmêtre can have a number of manifestations. However, they are all characterised by a disassociation of what is seen and what is heard. The acousmêtre opens a space outside the visible, while maintaining an unresolved tension as to where the voice is 'attached'. ${ }^{6}$ Unlike the imaginary voice in silent films which is associated with what is seen 'in' the image, the voice of the acousmetre opens a space outside or hidden inside what is seen.

In summary, Chion's analysis identifies three types of voices unique to the film format:

1. The imagined voice of the silent film

2. The synchronised voice of the talking film

3. The acousmêtre 
While Chion primarily devotes his analysis to the acousmetre, also the first type is considered aesthetically relevant. In Blanche-Neige Lucie both are present. The work presents Dolène's voice by way of subtitles while she sits tacitly, and the subtitles can be read as a train of thought. Hereby the work opens an imaginary space for a possible voice without it actually being heard. But what about the acousmêtre? As mentioned, we hear Dolène sing in the video. However, the vocal qualities of the song coming from her mouth are immediately recognisable as belonging to someone else. The effect of hearing the familiar voice of Snow White is surprising and powerful. ${ }^{7}$ The work creates a moment of confusion and thereby evokes the surreal image of the woman Lucie Dolène singing with the voice of Snow White. This voice is acousmatic in nature. As such, the work opens two virtual presences with regard to the voice: One is the imagined voice of Dolène, which is triggered by the use of subtitles, and the other is the perceived source of the song. What one could consider the proper audible voice of Lucie Dolène remains unheard.

\section{A third memory}

Huyghe pursues a similar effect in one of his other video works, The Third Memory. Here Huyghe lets the homosexual bank robber John Wojtowicz re-enact the sequence of events during a bank robbery gone wrong. The bank robbery that ended with Wojtowicz being captured took place in 1972 and later became the subject of Sidney Lumet's film Dog Day Afternoon from 1975 starring Al Pacino. Wojtowicz, in response, accused Warner Brothers of first exploiting and capitalising on the events without him benefitting and, second, distorting the sequence of events in the Hollywood production. In Huyghe's work the now older Wojtowicz, a large man, tries to correct the errors. While holding a shotgun he commands the other actors around in a TV studio re-creation of the bank.

The final image of the video differs from the remainder of the work. It is video-filmed footage where you see a young man moving agitatedly outside the bank, shouting 'You got it! You got it!' The quality of the image is so grainy that you cannot make out the features of his face; but the movements, body posture and voice resemble Al Pacino's. It is only on closer inspection that you notice that the man is wearing a T-shirt, whereas in Lumet's film Pacino is wearing a white shirt.

The video shows how memory integrates various elements disregarding whether they are fictional or 'real'. This goes for the audience's experience, and it is clear that also Wojtowicz occasionally confuses the actual events and Sidney Lumet's film. ${ }^{8}$ Paradoxically the video footage that you would expect to separate the real events from the fictional account has the opposite effect in Huyghe's work. In the small clip fiction and documentary run together. The fictional and 'true' accounts cannot be distinguished by the media document meant to clarify the distinction. 
The experienced confusion is caused by the fact that the memory of Al Pacino in the role of Wojtowicz is a much more immediate figure of reference than the now larger and older body of Wojtowicz as he appears in the reconstruction. A similar effect is found in Blanche-Neige Lucie. For the audience, the voice of Snow White is associated with the cartoon character rather than the woman. Through this confusion Huyghe's film suggests an image of the woman Lucie Dolène that sings with the voice of Snow White.

Rather than adding up to a critique of a process of mediation, where the line between reality and fiction is blurred, Huyghe's work suggests that experience and memory unfold within a dynamic that cannot be understood without this very process.

\title{
Dubbing
}

In Blanche-Neige Lucie the tension regarding the source of the voice is doubled, as it also relates to Lucie Dolène's role as a dubbing actor and to the dubbing theme. As such the work suggests a mirror reflection of the dubbing situation, where she is the one being dubbed. The phenomenon of dubbing has been scrutinised by Mikhael Yapolsky. In the article 'Voice Devoured: Artaud and Borges on Dubbing' (Yapolsky, 1993) he traces the figure of dubbing to, among others, Artaud's reflections on the Jewish figure of the dybbuk, as someone speaking through the mouth of someone else. He also quotes J. L. Borges, who in an article notes with distaste the surprising and disturbing effect of experiencing a body speaking with an alien voice and likens it to a chimera:

\begin{abstract}
The Greeks engendered the chimera, a monster with the head of a lion, the head of a dragon, and the head of a goat; the theologians of the second century, the Trinity, in which the Father, the Son and the Holy Ghost are inextricably linked; the Chinese zoologists, the ti-yiang, a bright red, supernatural bird equipped with six feet and six wings but with neither face nor eyes; the geometrists of the nineteenth century, the hypercube, a four-dimensional figure that encloses an infinite number of cubes and is bounded by eight cubes and twenty-four squares. Hollywood has just enriched this frivolous, teratological museum: by means of a perverse artifice called dubbing, they offer monsters that combine the well-known features of Greta Garbo with the voice of Aldonza Lorenzo. (Borges, 1988, p. 62)
\end{abstract}

The phenomena that emerges from Huyghe's work is just such a chimera. ${ }^{9}$

\section{Final thoughts}

Huyghe's video works explore the effects of fictional accounts not as a secondary element 'after the fact' or outside reality. Rather, Huyghe's work explores the impact 
that fictions have on reality. Phenomena, in this case a film, are defined by way of their affective potential, rather than their formal properties, as entities considered in isolation. In this perspective reality and fiction are part of the same circuit and may interfere with each other in unpredictable ways. ${ }^{10}$ It is also from this perspective that Huyghe's work can be considered topological. ${ }^{11}$ Through his works Huyghe points out an area of indeterminism - a grey area where a fictional narrative affects the surroundings on different levels.

In the cases of John Wojtowicz and Lucie Dolène both find their individual identity in relation to a production of a narrative, where the production itself in one way or another involves them as individuals. Even if they are positioned differently in relation to a process of production, they both suffer the consequences of the fictional narrative. (Lucie as mentioned had to go through a legal procedure, and Wojtowicz's claim was never acknowledged).

On a different level the works aim to demonstrate the extent to which narratives affect memory and thereby frame the interpretation of what is sensorially perceived. As such the works are less about the disruption of the perceived order of reality caused by media technology, as the critique of schizophonia would have it. Rather, they explore a space created by a state of ubiquitous mediation that is an order of reality. The ubiquitous presence of mediation creates certain conditions where the notion of human identity is a product of a process where various elements, either fictional or factual, are intertwined.

In Huyghe's works the figure of the voice becomes an entry point to understanding the complex dynamic where an individual is not distinct from a relational network, but rather an inseparable part of it. In this perspective the voice as an object is not to be understood as a signifier of a pre-existing individual, but rather as an element in the set of relations that defines the individual and ties it to an environment.

Blanche-Neige Lucie aims to momentarily bring forth the chimera figure in the dubbing, thereby pointing to the fact that what is experienced is not just a product of the immediate medial circumstances, but also of a much more general horizon of mediated phenomena.

\section{References}

Barikin, A. (2015). Parallel Presents: The Art of Pierre Huyghe. Cambridge, Mass.: MIT Press.

Barthes, R. (2010). Camera Lucida. Hill and Wang.

Borges, J.L. (1988). On dubbing. In: C.E. (Ed.), Borges in/and/on film. Lumen Books.

Chion, M. (1999). The Voice in Cinema. New York: Columbia University Press.

Connor, S. (2012). Panophonia. Manuscript. Retrieved from: http://www.stevenconnor.com/panophonia/panophonia.pdf

Connor, S. (2001). Dumbstruck: A Cultural History of Ventriloquism. Oxford University Press. 
Dolar, M. (2006). A Voice And Nothing More. Cambridge, Mass.: MIT Press.

Huyghe, P. (1997). The Silent Voice and the Landscape of the Narrative. In: 1 minute scenario. Le Printemps de Cahors.

Kassabian, A. (2013). Ubiquitous Listening - Affect, Attention, and Distributed Subjectivity. University of California Press.

Parreno, P. (2008). The Invisible Ape Boy. In: Dominique Gonzalez-Foerster: TH. 2058. London: Tate.

Robbins, D. (2006). Warm Science Fiction. In: The velvet grind: selected essays, interviews, satires (19832005). Zürich: JRP/Ringier. Dijon: Les Presses du reel.

Schafer, R.M. (1977). The Soundscape: our sonic environment and the tuning of the world. Rochester, Vt.: Destiny Books.

Sterne, J. (2003). The Audible Past, Cultural Origins of Sound Reproduction. Durham: Duke University Press.

Toop, D. (2011). Sinister Resonance. Continuum.

Yapolsky, M. (1993). Voice Devoured: Artaud and Borges on Dubbing. October, 64.

Žižek, S. (2012). Less than Nothing: Hegel and the shadow of dialectical materialism. London \& New York: Verso.

\section{Notes}

1 The often quoted statement that Hitler's success was unthinkable without the loudspeaker is the telling example of how Schafer sees the forces at play in the modern state of schizophonia.

2 See for example Sterne (2003, p. 287ff.).

3 Other examples include Celine Dion singing a duet with Frank Sinatra. The temporal dislocation inherent in schizophonic voice phenomena is also an aspect of historical recordings. This was explored in Susan Hiller's work The Last Silent Film (2008) that staged anthropological recordings of languages that are no longer spoken and for that reason can no longer be understood. Similarly, and more recently in the Latin American Pavilion at the Venice Biennale in 2015 endangered languages could be heard over a number of loudspeakers. A different thematic angle is found in the archive of 'paranormal' audio recordings of Friedrich Jürgensen a project that is curated by the Swedish artist Carl Michael von Hauswolff (discussed in Toop, 2011, p. 151f).

4 See also Anahid Kassabian's analysis of ubiquitous music and the corresponding 'ubiquitous' mode of listening (Kassabian, 2013).

5 The question of format is crucial in Huyghe's work, which adopts formats such as a billboard, opera and in this case film. A format like film or snapshot photos is not just defined by a set of standards given by the technical-formal characteristics of a given medium. A particular format entails standards of how it is produced, a standard of consumption etc. As David Robbins elaborates in a text on Pierre Huyghe: 'To engage a format is not only to engage a manipulable representative of the everyday, it is also to engage the host of abstractions-systematization, standardization, replicability, dissemination, and so on - that underwrite all formats. Any single format is the tip of an enormous iceberg of compacted, machine-inspired abstraction' (Robbins, 2006, p. 239).

6 Obviously the acousmetre is akin to the schizophonic voice. However, it is important to stress with regard to Chion's analysis that it stays within the frame of the film format. The effect of the acousmetre must be understood against the background of certain format conventions or what Chion terms the audio-visual 'contract'.

7 Even in its French translation the vocal qualities and the melody are recognisable.

8 In a slip of the tongue Wojtowicz refers to the actual events as 'in the real movie'. Adding to the blurring of cause and effect Wojtowicz also notes that immediately prior to the robbery 
the robbers had been to the cinema and watched The Godfather starring Al Pacino and that the film had inspired him to use a note during the robbery.

9 A different kind of chimera is found in Huyghe's video work One Million Kingdoms, where the animated figure Annlee, a generic Japanese anime character bought by Huyghe and Philippe Parreno, is walking through a computer-generated lunar-like landscape that turns out to be a dynamic rendition of a $3 \mathrm{~d}$ spectrogram of an audible voice. This voice that both emanates from the mouth of the animated character and determines the shape of the landscape is recognisable as that of the astronaut Neil Armstrong.

10 In the introductory text running across the screen in One Million Kingdoms the geographical location of Snæfellsjökull in Island is said to be a point of intersection between various fictional and factual accounts: It was the location of the NASA simulation of the lunar landing and the entry point to the centre of the Earth in Jules Verne's novel Journey to the Center of the Earth.

11 Amelia Barikin (2015, p. 183ff) has considered the topological aspects of Huyghe's work. 